\title{
Minimally invasive esophagectomy in achalasia: a more liberal approach to esophageal resection
}

\author{
Eduardo Crema ${ }^{1}$, Júverson Alves Terra Júnior ${ }^{1}$, Guilherme Azevedo Terra ${ }^{2}$, Celso Junior de Oliveira Teles ${ }^{2}$, Alex \\ Augusto da Silva ${ }^{1}$
}

${ }^{1}$ Department of Surgery, Federal University of Triângulo Mineiro, Uberaba, MG 38025-440, Brazil.
${ }^{2}$ School of Medicine, Federal University of Triângulo Mineiro, Uberaba, MG 38025-440, Brazil.

Correspondence to: Dr. Eduardo Crema, Department of Surgery, Federal University of Triângulo Mineiro, Uberaba, MG 38025-440, Brazil. E-mail: cremauftm@mednet.com.br

How to cite this article: Crema E, Júnior JAT, Terra GA, de Oliveira Teles CJ, da Silva AA. Minimally invasive esophagectomy in achalasia: a more liberal approach to esophageal resection. Mini-invasive Surg 2017;1:160-6.

\author{
Article history: \\ Received: 12 Jul 2017 \\ First Decision: 1 Aug 2017 \\ Revised: 31 Aug 2017 \\ Accepted: 28 Sep 2017 \\ Published: 28 Dec 2017
}

Key words:

Advanced megaesophagus,

vagal preservation,

transhiatal esophagectomy,

laparoscopic esophagectomy

\begin{abstract}
\end{abstract}
\section{INTRODUCTION}

The scientific rationale for choosing the best surgical treatment for a condition is to offer patients a procedure that removes or abrogates the symptoms and adverse risks of the condition, thus reducing the number of complications and the mortality rate. The advent of minimally invasive abdominal and thoracic surgeries has led to a meaningful reduction in complication and mortality rates among patients undergoing esophagectomy, especially when used for the treatment of benign diseases such as megaesophagus ${ }^{[1]}$.

Advanced megaesophagus mainly affects young male adults. It is a chronic progressive motor disorder of esophageal peristalsis that results in dilatation, tortuosity, and elongation of the esophagus. Megaesophagus is commonly associated with pulmonary complications due to acute or chronic bronchoaspiration, and with a higher frequency of epidermoid esophageal

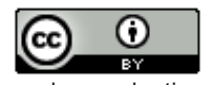
License (https://creativecommons.org/licenses/by/4.0/), which permits unrestricted use, distribution, and reproduction in any medium, as long as the original author is credited and the new creations are licensed under the identical terms.

For reprints contact: service@oaepublish.com

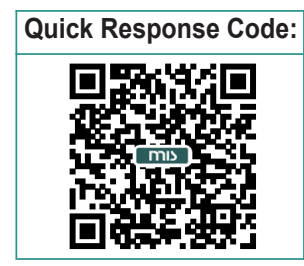


cancer $^{[2,3]}$ secondary to stasis, chronic esophagitis, intraesophageal $\mathrm{pH}$ changes ${ }^{[4]}$, and the presence of bacteria $^{[5]}$ and viruses such as human papilloma virus $(\mathrm{HPV})^{[6]}$, in addition to a high prevalence of Helicobacter pylori in the esophageal mucosa ${ }^{[7]}$.

Esophagectomy for the treatment of advanced megaesophagus, consisting of right thoracotomy, laparotomy, and cervicotomy, was reported by Camara Lopes and Ferreira-Santos in 1963. Also, in Brazil, DePaula et al..[8], Crema et al..[9] and Crema et al..[10] published their first results of full laparoscopic transhiatal esophagectomy for the treatment of megaesophagus, including removal of a surgical specimen and esophagogastric anastomosis through cervical incision. As megaesophagus affects the myenteric plexus that is located between the smooth muscle layers, subtotal resection of the organ theoretically cures the disease because striated muscles, which are not innervated by myenteric plexuses, predominate in the proximal third. Analysis of radiologic-manometric correlations showed an amplitude of esophageal body contraction of $<20 \mathrm{mmHg}$ in all cases radiologically classified as megaesophagus grade IV and in $35.7 \%$ of cases classified as grade III, defined by us as functionally advanced $^{[11]}$.

In a study investigating 31,769 patients with achalasia in the United States between 2003 and 2010, esophagectomy was performed in 785 cases $(2.5 \%)$, with an associated intrahospital mortality rate of $1.96 \%$, similar to that with endoscopic treatment $(1.17 \%)$, and Heller myotomy was performed in 15,567 cases $(49.0 \%)^{[12]}$. Various authors recommend esophageal resection in the case of recurrence or persistence of symptoms after Heller surgery ${ }^{[13-17]}$. Csendes et al. ${ }^{[18]}$ reported poor results of Heller surgery in $20 \%$ of patients after 10 years of follow-up and in 35\% after 20 years. Furthermore, $4.5 \%$ of these patients developed esophageal cancer. In a 15-year follow-up study of 448 patients after Heller surgery, Leeuwenburgh et al. ${ }^{[19]}$ found epidermoid cancer in $2.7 \%$ and adenocarcinoma in Barrett's esophagus in $0.7 \%$.

Crema et al. ${ }^{[6]}$ observed changes in esophageal $\mathrm{pH}$ (4 and 5 ) and a high prevalence of HPV subtypes 16 and 18 in the mucosa of patients with megaesophagus. These subtypes are directly associated with epidermoid esophageal cancer ${ }^{[20]}$.

Using a transhiatal approach in $94 \%$ of cases, Devaney et al. ${ }^{[21]}$ observed mortality in $2 \%$, complications in $30 \%$, and anastomosis dehiscence in $10 \%$ of cases, whereas $88 \%$ of the patients were satisfied with the procedure. Molena and Yang ${ }^{[22]}$ reported excellent results of using a transthoracic approach in esophagectomy and the stomach as the plasty organ. In Brazil, resection of the esophageal mucosa is preferentially performed for the treatment of advanced megaesophagus, in which a muscular tube is preserved through which the stomach is transposed to the cervical region ${ }^{[23]}$.

In cases of advanced and recurrent megaesophagus, minimally invasive transhiatal esophagectomy is an excellent surgical approach to eliminate dysphagia and prevent pulmonary complications resulting from bronchoaspiration and from the occurrence of tumors associated with chronic esophageal stasis.

\section{METHODS}

During the study period, 660 patients were treated. Of these, 346 (52.42\%) underwent Heller surgery combined with an antireflux valve, 231 (35.01\%) underwent transhiatal esophagectomy, and 83 (12.57\%) underwent esophageal dilatation due to possible clinical conditions for any surgical procedure.

Two hundred thirty-one patients, $152(65.8 \%)$ men and $79(34.2 \%)$ women, with a mean age of $52.46(19-80)$ years, were treated for advanced megaesophagus at the Department of Surgery, School of Medicine, Federal University, Uberaba, Brazil, between September 1996 and October 2016. Two hundred and ten patients $(90.91 \%)$ had chagasic megaesophagus and 21 patients $(9.09 \%)$ had idiopathic megaesophagus. The mean duration of the surgical procedure was 165 (100235) min, and all procedures were performed by the same team, with the responsible surgeon being one of the authors of the present study (Crema E). Of the 231 patients, $98(42.43 \%)$ had undergone at least some type of esophagogastric transition surgery 8-20 years before the study. All patients received information about the surgical procedure to be performed, and the protocol was approved by the Ethics Committee on Human Research of the School of Medicine of the Federal University, Uberaba, Brazil[ ${ }^{[9]}$.

\section{Surgical technique}

The patients were placed in the dorsal decubitus position on the operating table with the legs abducted. The surgeon was positioned between the legs, and an assistant (camera), on the left side of the patient. The monitor, when there was only one, was positioned on the right and at the head of the operating table. Five entry ports were used: 2 of $10 \mathrm{~mm}$ diameter and 3 of $5 \mathrm{~mm}$ diameter. One of the $10-\mathrm{mm}$ ports was situated in the midline between the xiphoid appendix and the navel for a $30^{\circ}$ eyepiece and the other was positioned in the left hemiclavicular line $5 \mathrm{~cm}$ from the costal margin (right hand of the surgeon). The $5-\mathrm{mm}$ 
ports were positioned in the right hemiclavicular line (left hand of the surgeon), $1 \mathrm{~cm}$ left from the xiphoid appendix (aspirator) and $15 \mathrm{~cm}$ left from the umbilical scar (esophageal separator).

Using a 12-mmHg pneumoperitoneum $\left(\mathrm{CO}_{2}\right)$, the procedure was started through ample dissection of the esophagogastric transition, restoring the abdominal esophagus with a Penrose drain or a flexible separator (EndoFlex, Medline, Mundelein, IL, USA). Dissection was continued with the esophageal body under direct vision, with preservation of the vagus nerves [Figure 1] and identification of the pleurae and pericardium. Hemostasis was achieved with monopolar cauterization or with UltraCision (UltraCision Inc., Smithfield, RI, USA) and/or clipping of the esophageal branches until the cervical region. The surgical dissection plane was close to the esophagus, thus preventing damage to the pleurae and mediastinal structures.

To obtain better access to the mediastinum during dissection of the thoracic esophagus, we routinely performed median transection of the diaphragm and placed the operating table in the Trendelenburg position.

After dissection of the abdominal and thoracic esophagus was completed, the stomach was prepared with release
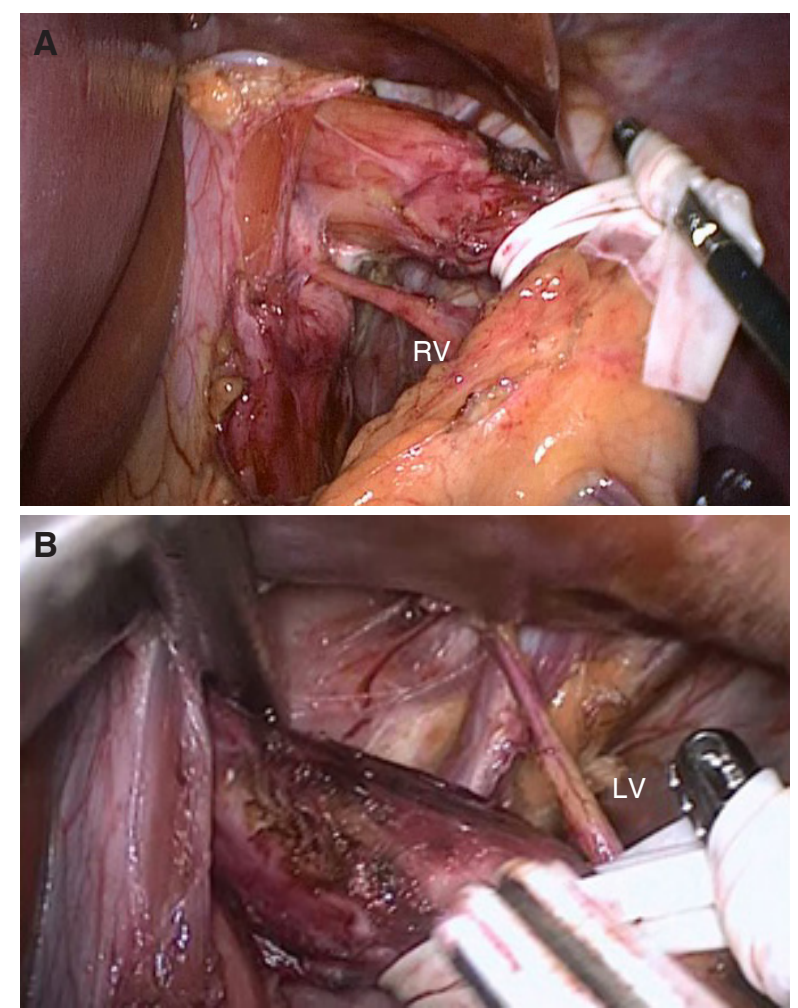

Figure 1: Completely dissected esophageal segment. Details of the right $(A)$ and left $(B)$ vagal trunks. RV: right vagal trunk; LV: left vagal trunk of the greater curvature. Monopolar electrocauterization and UltraCision were used for sectioning of the short gastric vessels and gastrocolic omentum. The gastroepiploic and left gastric vessels were ligated by double clipping, with preservation of the arch of the greater and lesser curvature. No pyloroplasty was performed during surgical treatment of advanced megaesophagus. After preparing the stomach, the cervical esophagus was dissected through a left cervicotomy. Owing to the delicate traction of the surgical specimen, the esophagus and proximal part of the stomach in the cervical region were exteriorized and the esophagogastric transition was sectioned with a cutting linear stapler with a $75-\mathrm{mm}$ green load. The passage of the esophagus and stomach was monitored during cervical traction of the esophagus under direct vision, using an eyepiece positioned in the inferior mediastinum.

An esophagogastric anastomosis was performed with manual continuous 3.0 monofilament sutures on a single plane between the posterior wall of the gastric fundus and a segment of the cervical esophagus, whose extension was approximately $4 \mathrm{~cm}$ so that the esophagogastric anastomosis would remain in the cervical region. No cervical or abdominal drainage was used.

The use of the whole stomach as the plasty organ is justified by the maintenance of better vascularization of the gastric body and fundus because of noninterruption of the rich vascular submucosal network. We therefore do not fabricate a gastric tube and do not interrupt the arcade of the greater and lesser curvature of the stomach. In addition, the stomach of patients with advanced megaesophagus is hypotrophied and has a tubuliform shape [Figure 2], which facilitates the transposition to the cervical region without the need for fabrication of a gastric tube.

During surgery, a nasoenteric tube was placed in the duodenum or gastric antrum for enteral nutritional support. Enteral diet was started on the second postoperative day and was maintained until the seventh day, when an oral diet was administered after radiologic confirmation of the absence of fistulas and good passage of contrast dye through the anastomosis.

A chest roentgenogram was obtained from all patients at the end of surgery in the operating room. In addition, all patients underwent radiologic contrast examinations and upper digestive endoscopy 12 months after surgery.

To analyze gastroesophageal reflux and esophagitis in the esophageal stump, 126 patients later ( 7 months 

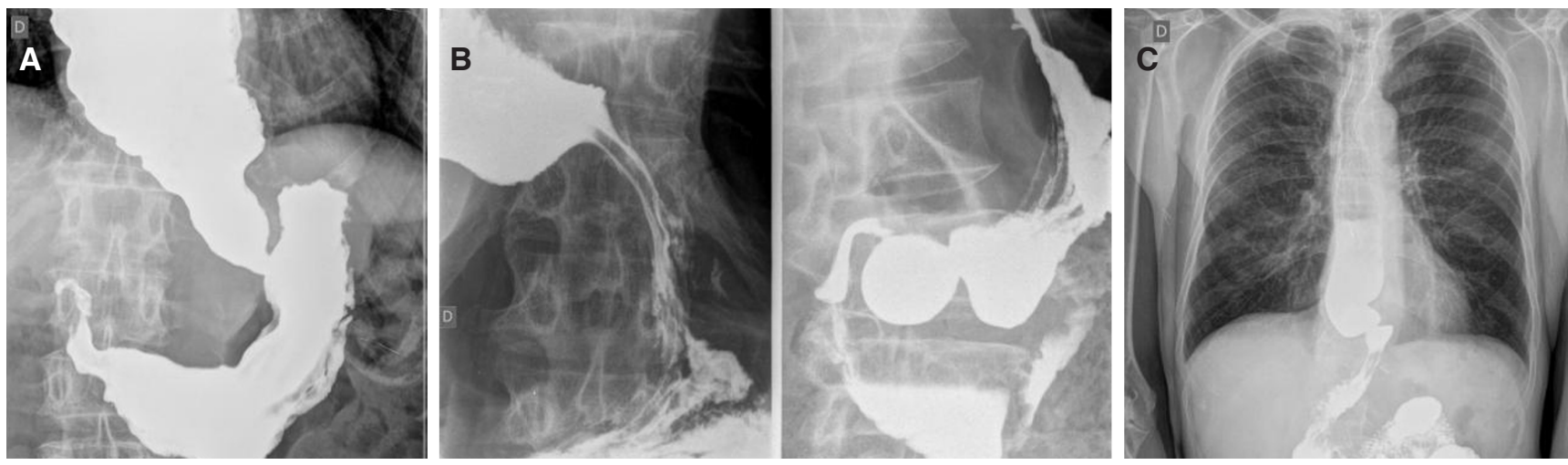

Figure 2: Preoperative images ( $A$ and $B)$. Postoperative control after 30 days $(C)$. All images show the tube-shaped stomach

to 20 years) underwent endoscopic submucosal dissection with a biopsy, esophagogastric manometry, and 24-h $\mathrm{pH}$ measurement in the esophageal stump. The sensor was placed $2 \mathrm{~cm}$ above the esophagogastric anastomosis, and its precise position was determined at the time of endoscopic examination ${ }^{[9]}$.

\section{RESULTS}

Immediate complications were observed in 37 patients (16.01\%): hemopneumothorax in 22 cases $(9.52 \%)$, gastric stasis in $11(4.76 \%)$, a cervical fistula in 11 $(4.76 \%)$, dysphonia in $18(7.8 \%)$, and mediastinitis in 1 case $(0.43 \%)$. Two patients $(0.86 \%)$ died: 1 patient with a pacemaker died of cardiorespiratory arrest on postoperative day 12 and the other patient died of mediastinitis on day 28 .

Late complications occurred in 23 patients (9.95\%). Ten patients $(4.33 \%)$ who developed stenosis were treated with endoscopic dilatation. Reoperation and anastomosis plasty were necessary in 1 case. Dysphonia occurred after 3 months in 8 patients $(3.46 \%)$. Gastric stasis occurred in 4 patients $(1.73 \%)$, and in 1 patient $(0.43 \%)$ who had an acute obstructive abdomen due to herniation of the transverse colon in the mediastinum. There was no case of severe esophagitis during a follow-up period of 7 months to 20 years.

Among the 136 patients (58.87\%) in whom the vagus nerves were preserved, only $3(2.2 \%)$ had gastricemptying problems during the immediate postoperative period vs. $8(8.42 \%)$ among the 95 patients $(41.13 \%)$ in whom vagus nerves were not preserved. Late gastricemptying problems were observed in 4 cases $(4.21 \%)$ in the group without vagal nerve preservation and in none of the cases with vagal preservation.

We highlight some important technical details of this procedure, including the use of the total stomach that, anatomically, owing to the chronic condition, already has a tubuliform shape. Pyloroplasty should not be performed to prevent duodenal alkaline reflux to the stomach and hyperchlorhydria. Preservation of the vagus nerves with maintenance of parasympathetic innervation permits maintaining irrigation of the stomach, thus reducing the rate of dehiscence and maintaining storage capacity, secretion, and gastric emptying. Another important technical detail is that the esophagogastric anastomosis is always located in the cervical region, a region characterized by positive pressure, thus preventing acid reflux from the stomach to the esophagus.

The patients had a nasoenteric tube introduced into the stomach and received an industrialized enteral diet ( $1.5 \mathrm{~g} / \mathrm{kg}$ body weight per day) for at least 14 days. After clinical and spirometric pulmonary evaluation, the patients underwent expiratory and inspiratory muscle training with a threshold device for 2 weeks.

Routine ultrasonography of the abdomen is important in the identification of cholelithiasis, as this association is found in $28.4 \%$ of patients with chagasic megaesophagus as a result of parasympathetic denervation of the gallbladder ${ }^{[24]}$. If present, cholecystectomy is performed during surgery.

On the day before surgery, a thick Fouchet or Levin oroesophageal tube is introduced, and the esophagus, which usually contains large amounts of food remnants, is cleaned mechanically with $0.9 \%$ saline.

It is important to point out that the anterior and posterior vagus nerve should be dissected before esophageal dissection and stomach preparation to avoid inadvertent sectioning of the vagal trunks in the cervical region. Pyloroplasty is not performed in patients with esophagopathy who do not have a megastomach to avoid reflux from the duodenum to the stomach, now positioned in the posterior mediastinum, a region of 
negative pressure. Another important factor is that the esophagogastric anastomosis remains in the cervical region, which is characterized by positive pressure, thus preventing reflux of gastric juice into the esophagus and consequent esophagitis. The latter occurs in the case of intrathoracic location of the anastomosis.

\section{DISCUSSION}

The minimally invasive technique is considered the gold standard for the treatment of megaesophagus. In its early stages, modified Heller surgery combined with a partial antireflux valve has been used with good results. In advanced stages of megaesophagus, minimally invasive transhiatal esophagectomy has been the technique of choice in most centers in Brazil.

Preoperative preparation is also of fundamental importance for good outcomes in these patients, who are usually malnourished and have pulmonary alterations. Chagasic patients exhibit different types of cardiac arrhythmias that should be corrected during the preoperative period. Our standardized protocol includes nutritional and pulmonary outpatient care for this purpose.

A standardized interdisciplinary protocol that comprises the preoperative, perioperative, and postoperative management of patients with megaesophagus is of fundamental importance to obtain satisfactory results in the treatment of this disease. Zamuner et al. ${ }^{[25]}$ evaluated the use of standardized protocols by multidisciplinary teams in the state of São Paulo, and concluded that the number of centers applying preestablished multidisciplinary protocols is small.

There is clear evidence that preservation of the vagus nerves permits maintenance of gastric emptying, acid secretion, and storage capacity of the stomach, as well as long-term weight maintenance. The results of minimally invasive approaches are consistent with the reduced number of major complications and low mortality rate.

Wang et al. ${ }^{[4]}$ observed atrophic gastritis in patients who underwent gastroplasty after esophagectomy without vagal nerve preservation.

Anatomically, the vagus nerves exhibit 2 trunks (83.4\%); these trunks are separated in $26.7 \%$ of patients, a communication between them is detected in $56.7 \%$, and 1 or 2 bifurcations occur in only $13.3 \%$ of patients ${ }^{[26]}$. Clinical and experimental studies have reported several benefits of preserving the vagus nerves. Using Congo red staining, Banki et al. ${ }^{[1]}$ demonstrated acid secretion in the stomach and maintenance of gastric emptying when the vagus nerve was preserved during esophagectomy. Preservation of the vagus nerves also permits the maintenance of parasympathetic irrigation of the stomach, reducing the rate of dehiscence in esophagogastric anastomoses. Furthermore, maintenance of the control of gastric emptying by preserving the vagus nerves reduced the rate of dumping episodes and diarrhea.

The benefit of vagal integrity goes beyond the maintenance of secretory function and gastric motility. Several experimental studies have demonstrated the importance of integrity of the vagus nerves for protection against bacterial translocation. Vagal nerve preservation significantly reduces infectious complications $^{[27]}$. Experimental studies have reported sepsis and faster death in vagotomized animals when compared to controls ${ }^{[28]}$. An increased degree of peritonitis and higher levels of inflammatory cytokines were also observed in vagotomized animals ${ }^{[29]}$.

Evidence of the physiological preservation of the vagus nerves is obtained by measuring the levels of pancreatic peptide after stimulation. Banki et al. ${ }^{[1]}$ observed a significant increase in pancreatic peptide levels when the vagus nerve was preserved during esophagectomy.

The objective of not performing pyloroplasty or pyloromyotomy is to avoid reflux of alkaline secretion from the duodenum to the stomach after gastric transposition to the mediastinum, a region of negative pressure, which would cause an increase in acid secretion from the stomach.

Crema et al. ${ }^{[30]}$ compared patients undergoing esophagectomy with and without vagotomy. The results showed a significant increase in pancreatic peptide levels after insulin-induced hypoglycemia in the group with preserved vagus nerve, which was not observed in vagotomized patients.

Our sample of patients undergoing esophagectomy included 21 patients (9.09\%) with idiopathic megaesophagus for whom serology and polymerase chain reaction results of esophageal tissues were negative for Trypanosoma cruzi. In a study conducted in Campinas-SP in which only serology was used for the diagnosis of Chagas disease, $21 \%$ of the patients had idiopathic megaesophagus ${ }^{[31]}$.

Esophagectomy with preservation of the vagal trunks has been used for the treatment of chagasic megaesophagus, although denervation of the entire 
parasympathetic autonomic nervous system occurs in this condition (digestive tract myenteric and submucosal plexuses). It is known that the chronically denervated stomach develops intrinsic mechanisms that maintain motility and emptying. In patients with idiopathic megaesophagus undergoing vagotomy, impairment of gastric emptying is observed during the first months after surgery. Previous studies have shown better gastric emptying after esophagectomy even in patients with chagasic megaesophagus and vagal nerve preservation.

With a standardized multidisciplinary protocol and a team adequately trained in laparoscopy, minimally invasive esophagectomy is an excellent option for the treatment of advanced megaesophagus. The technique is easily standardized and reproducible, and provides excellent postoperative outcomes.

\section{DECLARATIONS}

\section{Authors' contributions}

Surgical procedures: E. Crema, J.A.T. Júnior, A.A. da Silva

Monitoring of patients: G.A. Terra, C.J. de Oliveira Teles

\section{Financial support and sponsorship \\ None.}

\section{Conflicts of interest}

There are no conflicts of interest.

\section{Patient consent}

All patients were guided by the surgical technique and the risks inherent in the procedure.

\section{Ethics approval}

The procedure was approved by the Human Research Ethics Committee of the Federal University of Triângulo Mineiro.

\section{REFERENCES}

1. Banki F, Mason RJ, DeMeester SR, Hagen JA, Balaji NS, Crookes PF, Bremner CG, Peters JH, DeMeester TR. Vagal-sparing esophagectomy: a more physiologic alternative. Ann Surg 2002;236:324-35; discussion 335-6.

2. Eckardt VF, Hoischen T, Bernhard G. Life expectancy, complications, and causes of death in patients with achalasia: results of a 33-year follow-up investigation. Eur J Gastroenterol Hepatol 2008;20:956-60.

3. Banbury MK, Rice TW, Goldblum JR, Clark SB, Baker ME, Richter JE, Rybicki LA, Blackstone EH. Esophagectomy with gastric reconstruction for achalasia. $J$ Thorac Cardiovasc Surg 1999; $117: 1077-84$
4. Wang D, Zhang R, Sun K. The digestive functions of the stomach after esophagectomy with vagus nerve preserved or severed in esophageal cancer patients: a comparative study. Zhonghua Zhong Liu Za Zhi 2000;22:414-6. (in Chinese)

5. Eduardo C, Madureira AB, Lima VG, Castro AM, Silva AA, Junqueira IS. Microflora in chagasic megaesophagus. Rev Soc Bras Med Trop 2002;35:39-42. (in Portuguese)

6. Crema E, De Lima TS, Junqueira IS, Rodrigues Junior V, Terra Júnior JA, Silva AA. Prevalence study of esophageal HPV infection in patients with megaesophagus and correlation with in situ and 24-hour PH measurement. Bras J Video-Sur 2010;3:181-5.

7. Fonseca FM, Queiroz DM, Rocha AM, Prata A, Crema E, Rodrigues Junior V, Ramirez LE, Oliveira AG. Seroprevalence of Helicobacter pylori infection in chagasic and nonchagasic patients from the same geographical region of Brazil. Rev Soc Bras Med Trop 2012;45:194-8.

8. DePaula AL, Hashiba K, Ferreira EA, de Paula RA, Grecco E Laparoscopic transhiatal esophagectomy with esophagogastroplasty. Surg Laparosc Endosc 1995;5:1-5.

9. Crema E, Ribeiro LB, Terra JA Jr, Silva AA. Laparoscopic transhiatal subtotal esophagectomy for the treatment of advanced megaesophagus. Ann Thorac Surg 2005;80:1196-201.

10. Crema E, Ribeiro LB, Sousa RC, Terra Júnior JA, Silva BF, Silva AA, Silva AV. Laparoscopic transhiatal esophagectomy for the treatment of advanced megaesophagus. An analysis of 60 cases. Rev Col Bras Cir 2009;36:118-22. (in Portuguese)

11. Crema E, Cruvinel LA, Werneck AM, de Oliveira RM, Silva AA Manometric and radiologic aspects of Chagas' megaesophagus: the importance to its surgical treatment. Rev Soc Bras Med Trop 2003;36:665-9. (in Portuguese)

12. Molena D, Mungo B, Stem M, Lidor AO. Hospitalization for esophageal achalasia in the United States. World $J$ Gastrointest Endosc 2015;7:1096-102.

13. Loviscek MF, Wright AS, Hinojosa MW, Petersen R, Pajitnov D, Oelschlager BK, Pellegrini CA. Recurrent dysphagia after Heller myotomy: is esophagectomy always the answer? J Am Coll Surg 2013;216:736-43; discussion 743-4.

14. Orringer MB, Stirling MC. Esophageal resection for achalasia: indications and results. Ann Thorac Surg 1989;47:340-5.

15. Devaney EJ, Lannettoni MD, Orringer MB, Marshall B Esophagectomy for achalasia: patient selection and clinical experience. Ann Thorac Surg 2001;72:854-8.

16. Rodgers M, Jobe BA, O'Rourke RW, Sheppard B, Diggs B, Hunter JG Case volume as a predictor of inpatient mortality after esophagectomy. Arch Surg 2007;142:829-39.

17. Patti MG, Molena D, Fisichella PM, Whang K, Yamada H, Perretta S, Way LW. Laparoscopic Heller myotomy and Dor fundoplication for achalasia: analysis of successes and failures. Arch Surg 2001;136:870-7.

18. Csendes A, Braghetto I, Burdiles P, Korn O, Csendes P, Henríquez A. Very late results of esophagomyotomy for patients with achalasia: clinical, endoscopic, histologic, manometric, and acid reflux studies in 67 patients for a mean follow-up of 190 months. Ann Surg 2006;243:196-203.

19. Leeuwenburgh I, Scholten P, Alderliesten J, Tilanus HW, Looman CW, Steijerberg EW, Kuipers EJ. Long-term esophageal cancer risk in patients with primary achalasia: a prospective study. $\mathrm{Am} \mathrm{J}$ Gastroenterol 2010;105:2144-9.

20. Li SY, Li Y, Shen LP, Wu XZ, Zhao XY, Zhou L, Liu HT, Zeng Y. Meta analysis on etiological relationship between human papillomavirus and esophageal carcinoma. Zhonghua Shi Yan He Lin Chuang Bing Du Xue Za Zhi 2009;23:85-7. (in Chinese)

21. Devaney EJ, Lannettoni MD, Orringer MB, Marshall B Esophagectomy for achalasia: patient selection and clinical experience. Ann Thorac Surg 2001;72:854-8. 
22. Molena D, Yang SC. Surgical management of end-stage achalasia. Semin Thorac Cardiovasc Surg 2012;24:19-26.

23. de Oliveira GC, da Rocha RL, Coelho-Neto Jde S, Terciotti-Junior V, Lopes LR, Andreollo NA. Esophageal mucosal resection versus esophagectomy: a comparative study of surgical results in patients with advanced megaesophagus. Arq Bras Cir Dig 2015;28:28-31. (in English, Portuguese)

24. Crema E, Silva EC, Franciscon PM, Rodrigues Júnior V, Martins Júnior A, Teles CJ, Silva AA. Prevalence of cholelithiasis in patients with chagasic megaesophagus. Rev Soc Bras Med Trop 2011;44:324-6.

25. Zamuner M, Herbella FA, Aquino JL. Standardized clinical pathways for esophagectomy are not a reality in Brazil, even with a high prevalence of esophageal cancer and achalasia. Arq Bras Cir Dig 2015;28:190-2.

26. Herbella FA, Regatieri CV, Moreno DG, Matone J, Del Grande JC. Vagal integrity in vagal-sparing esophagectomy: a cadaveric study. Dis Esophagus 2006;19:406-9.

27. Peyre CG, DeMeester SR, Rizzetto C, Bansal N, Tang AL, Ayazi S, Leers JM, Lipham JC, Hagen JA, DeMeester TR. Vagal-sparing esophagectomy: the ideal operation for intramucosal adenocarcinoma and barrett with high-grade dysplasia. Ann Surg 2007;246:665-71; discussion 671-4.

28. Borovikova LV, Ivanova S, Zhang $\mathrm{M}$, Yang $\mathrm{H}$, Botchkina GI, Watkins LR, Wang H, Abumrad N, Eaton JW, Tracey KJ. Vagus nerve stimulation attenuates the systemic inflammatory response to endotoxin. Nature 2000;405:458-62.

29. van Westerloo DJ, Giebelen IA, Florquin S, Daalhuisen J, Bruno MJ, de Vos AF, Tracey KJ, van der Poll T. The cholinergic antiinflammatory pathway regulates the host response during septic peritonitis. J Infect Dis 2005;191:2138-48.

30. Crema E, Castro LGP, Junqueira IS, Gomes RAS, Terra GA, Terra Júnior JA, Silva AA. Vagus nerve integrity in patients who underwent laparoscopic esophagectomy for the treatment of megaesophagus. Braz J Video-Sur 2013;6:097-102.

31. Oliveira GC, Lopes LR, Andreollo NA, Coelho Neto JS. Surgically treated megaesophagus: epidemiological profile of patients operated in the Clinical Hospital of the State University of Campinas between 1989 and 2005. Rev Soc Bras Med Trop 2008;41:183-8. (in Portuguese) 